\title{
Somatostatin Receptor (SSTR) Subtype-selective Analogues Differentially Suppress In Vitro Growth Hormone and Prolactin in Human Pituitary Adenomas Novel Potential Therapy for Functional Pituitary Tumors
}

\author{
Ilan Shimon, ${ }^{\star}$ Xinmin Yan, ${ }^{\star}$ John E. Taylor, ${ }^{\ddagger}$ Martin H. Weiss, ${ }^{\S}$ Michael D. Culler, ${ }^{\star}$ and Shlomo Melmed* \\ *Department of Medicine, Cedars-Sinai Research Institute, UCLA School of Medicine, Los Angeles, California 90048; ${ }^{*}$ Biomeasure Inc., \\ Milford, Massachusetts 01757; and ${ }^{\S}$ Department of Neurosurgery, University of Southern California School of Medicine, Los Angeles, \\ California 90033
}

\begin{abstract}
Previously, we have shown somatostatin receptor (SSTR) subtype-specific regulation of growth hormone (GH), thyroid-stimulating hormone, and prolactin (PRL) secretion in human fetal pituitary cultures, where GH and thyroid-stimulating hormone are mediated by both SSTR2 and SSTR5, whereas SSTR2 preferentially mediates PRL secretion. We now tested SSTR subtype-selective analogues in primary human GH- and PRL-secreting pituitary adenoma cultures. Analogue affinities determined by membrane radioligand binding in cells stably expressing human SSTR forms were either SSTR2 or SSTR5-selective. Analogues preferential either for SSTR2, including octreotide, lanreotide, and novel compounds with improved affinity for SSTR2, or new SSTR5-selective compounds suppressed GH in tumor cell cultures (up to $44 \%$ of control; $P<0.0005$ ). However, novel analogues from both groups were $30-40 \%$ more potent than octreotide and lanreotide in suppressing GH $(P<0.05)$. Heterologous analogue combinations containing both SSTR2and SSTR5-selective compounds were more potent in decreasing GH than analogues used alone $(P<0.05)$, or than combinations of compounds specific for the same receptor subtype $(P<0.005)$. In contrast, SSTR2-selective analogues did not suppress PRL release from six cultured prolactinomas studied. However, new SSTR5-selective analogues suppressed in vitro PRL secretion $(30-40 \% ; P<0.05)$ in four of six prolactinomas. These results suggest that both SSTR2 and SSTR5 are involved in GH regulation in somatotroph adenoma cells, whereas SSTR5 exclusively regulates PRL secretion from prolactinoma cells. Thus, somatostatin analogues with improved selective binding affinity for these receptor subtypes may be effective in the treatment of either GH- or PRL-secreting adenomas. (J. Clin. Invest. 1997. 100: 2386-2392.) Key words: prolactinoma • acromegaly $\bullet$ somatostatin receptor $\cdot$ prolactin $\cdot$ growth hormone
\end{abstract}

Address correspondence to Shlomo Melmed, M.D., Division of Endocrinology and Metabolism, Cedars-Sinai Medical Center, 8700 Beverly Blvd., B-131, Los Angeles, CA 90048. Phone: 310-855-4691; FAX: 310-967-0119; E-mail: Melmed@CSMC.edu

Received for publication 19 May 1997 and accepted in revised form 25 August 1997.

J. Clin. Invest.

(C) The American Society for Clinical Investigation, Inc. 0021-9738/97/11/2386/07 \$2.00

Volume 100, Number 9, November 1997, 2386-2392

http://www.jci.org

\section{Introduction}

Prolactinomas and growth hormone $(\mathrm{GH})^{1}$-cell adenomas are the most common functioning pituitary adenomas $(1,2)$, together comprising $80 \%$ of these tumors. These monoclonal micro- or macroadenomas (3) are treated either medically or surgically. Prolactinomas are treated effectively with dopamine agonists in $\sim 70 \%$ of patients $(1,4,5)$. However, one-third of treated patients do not achieve normal prolactin (PRL) levels while on bromocriptine, more often in those harboring invasive macroadenomas with high baseline PRL levels. These patients are usually referred for pituitary surgery, as there are no effective medical alternatives to dopamine agonists for treating PRL-secreting tumors. GH-cell adenomas are less responsive to the available treatment modalities, and only $50-60 \%$ of patients are cured after pituitary surgery $(6,7)$. However, surgical remission rates decline sharply when these tumors are locally invasive. Moreover, normalization of GH and IGF-I levels occurs only in about half of acromegalic patients treated with the long-acting somatostatin analogue, octreotide (7-9).

Somatostatin exerts its biological effects through a family of $\mathrm{G}$ protein-associated receptors with seven transmembrane domains. At least five somatostatin receptor (SSTR) subtypes have been cloned (10), and are termed SSTRs 1-5. The human pituitary gland expresses SSTR1, 2, and $5(11,12)$, whereas human pituitary adenomas contain SSTR1, 2, 3, and 5 (11-14). The clinically available somatostatin analogues, octreotide and lanreotide (15), which are used to control GH secretion in acromegalic patients, bind efficiently to SSTR2 and with lower affinity to SSTR5.

Recently, we have studied anterior pituitary hormone regulation selectively mediated by different SSTR subtypes using receptor-specific somatostatin analogues in primary human fetal pituitary cultures (16), and we determined the role of both SSTR2 and SSTR5 in GH and thyroid-stimulating hormone regulation. However, PRL secretion was suppressed in fetal pituitary cultures only by SSTR2-specific compounds. Moreover, we have demonstrated expression of both SSTR2 and SSTR5 receptor subtypes in tumor tissue derived from patients harboring GH- and PRL-cell adenomas $(13,14)$. To investigate the involvement of SSTR2 and SSTR5 in GH and PRL regulation in human somatotroph and lactotroph adenomas and their potential for therapeutic application, we examined in vitro effects on GH and PRL secretion from somatotrophinomas and prolactinomas using novel SSTR subtype-preferential analogues for these receptors. Availability of these new compounds directed against specific SSTR subtypes has allowed us to identify novel candidates for peptidometic therapy of these tumors.

1. Abbreviations used in this paper: GH, growth hormone; PRL, prolactin; SSTR, somatostatin receptor. 
Table I. SSTRs Binding Affinity of Somatostatin Analogues

\begin{tabular}{lcc}
\hline & \multicolumn{2}{c}{ Receptor subtype affinity $(\mathrm{nM}) *$} \\
\cline { 2 - 3 } \multicolumn{1}{c}{ Compound } & SSTR2 & SSTR5 \\
\hline Somatostatin-14 & 0.23 & 0.88 \\
Octreotide & 0.56 & 7 \\
Lanreotide & 0.75 & 5.2 \\
BIM-23023 & 0.42 & 4.2 \\
BIM-23190 & 0.34 & 11.1 \\
BIM-23197 & 0.19 & 9.8 \\
BIM-23052 & 11.9 & 1.2 \\
BIM-23268 & 15.1 & 0.37 \\
\end{tabular}

* Subtype affinity was determined by radioligand membrane receptor binding assays in Chinese hamster ovary cells expressing human SSTR2 gene or SSTR5 cDNA (16).

\section{Methods}

Somatostatin analogues. Somatostatin-14, BIM-23014 (lanreotide), BIM23023, BIM-23052, BIM-23268, BIM-23190, and BIM-23197 were provided by Biomeasure Inc. (Milford, MA). The amino acid structures of these analogues and the radioligand receptor binding assays to determine the specific binding affinities of the compounds for the different human SSTRs have been reported previously (16). SMS 201-995 (octreotide) was obtained from Novartis (East Hanover, NJ). Analogues were dissolved in $0.01 \mathrm{M}$ acetic acid and $0.1 \%$ BSA, and frozen at $-20^{\circ} \mathrm{C}$ until used. Table I summarizes the binding affinities for SSTR2 and SSTR5 of the different somatostatin analogues used. The compounds can be classified as those selectively preferential for SSTR2 (octreotide, lanreotide, BIM-23023, -23190, and -23197) or for SSTR5 (BIM-23052, -23268). Somatostatin-14 has high affinity for both receptor subtypes. The affinities of all the analogues (except somatostatin-14) for SSTR1, 3, and 4 are very low, and are not shown in Table I.

Adenoma cell culture. Six GH-secreting pituitary adenomas and six PRL-secreting tumor specimens were obtained at the time of transsphenoidal surgery. The collection and use of tumor samples were in accordance with the guidelines of the local committee on human research. Clinical characteristics of the patients are presented in Tables II and III. Tumor specimens were cultured as described (16). Briefly, specimens were washed in DME with $0.3 \%$ BSA, minced, and enzymatically dissociated using $0.35 \%$ collagenase and $0.1 \%$ hyaluronidase (Sigma Chemical Co., St. Louis, MO) for $1 \mathrm{~h}$. Cell suspensions were filtered and resuspended in low glucose DME with 10\% FBS and antibiotics before seeding in 48-well tissue culture plates $(\sim 5 \times$ $10^{4}$ cells/well; 50-80 wells/tumor) in $0.5 \mathrm{ml}$ medium for $96 \mathrm{~h}$, at $37^{\circ} \mathrm{C}$, $5 \% \mathrm{CO}_{2}$. Medium was changed before treatment to serum-free de-

Table II. Clinical Characteristics of Acromegalic Patients

\begin{tabular}{lcccccl}
\hline No. & Sex & Age & GH & IGF-I & Tumor size & $\begin{array}{c}\text { Medical } \\
\text { therapy }\end{array}$ \\
\hline & & & $n g / m l$ & $n g / m l$ & $c m$ & \\
1 & F & 22 & 70 & 2176 & Macro; invasive & Octreotide \\
2 & F & 19 & NA & NA & $1.6 ;$ invasive & None \\
3 & M & 58 & 15 & 856 & $1.0 ;$ noninvasive & None \\
4 & F & 42 & 15 & 625 & $1.5 ;$ noninvasive & None \\
5 & M & 36 & 63 & 820 & Macroadenoma & None \\
6 & F & 22 & NA & NA & $0.6 ;$ noninvasive & None \\
& & & & & &
\end{tabular}

$N A$, not available. fined DME, and cell cultures were treated for $3 \mathrm{~h}$ with $10-100 \mathrm{nM}$ somatostatin analogues (six to eight wells for each analogue), combinations of compounds, or control (vehicle solution only), after which medium was frozen for later hormone measurements.

For the GH-cell adenoma culture studies we used the two clinically available somatostatin analogues, octreotide and lanreotide, and somatostatin-14, and compared them to novel analogues with preferential binding for either SSTR2 (BIM-23190, -23197) or SSTR5 (BIM23268, which we found to be more effective than BIM-23052). The compounds used to study the PRL-secreting adenomas included octreotide or lanreotide, somatostatin-14, and one or more representatives from the two receptor-selective analogue groups. Most of the tumors did not respond to $10 \mathrm{nM}$ concentrations, and thus were treated with $100 \mathrm{nM}$ analogues. For combination studies, submaximal analogue concentrations $(40-50 \mathrm{nM})$ were used.

Hormone assays. Human GH levels were measured by RIA and PRL by immunoradiometric assay (both obtained from Diagnostic Products Corp., Los Angeles, CA), after appropriate sample dilutions.

Statistical analysis. Data were analyzed by one-way ANOVA with planned contrasts, and two-sided $P$ values $<0.05$ for the contrasts between hormone suppression by novel analogues and octreotide/lanreotide were considered significant. Results are expressed as mean \pm SEM.

\section{Results}

GH-cell tumor cultures. Specimens cultured from six patients with $\mathrm{GH}$-secreting adenomas were studied. Somatotroph adenoma cells obtained from patient 1 (Table II) did not respond to either octreotide or lanreotide (10 nM; Fig. $1 A)$, and BIM23197 was the only somatostatin analogue that significantly suppressed in vitro GH secretion from this tumor $(26 \% ; P<$ $0.05)$. This patient had recurrent resection of an invasive macroadenoma, and did not respond to preoperative octreotide administration. Cell cultures derived from tumor 2 were treated with $100 \mathrm{nM}$ concentrations of the different analogues. Octreotide, lanreotide, and somatostatin-14 decreased $\mathrm{GH}$ secretion by $\sim 25 \%(P<0.05$; Fig. $1 B)$, whereas the novel compounds BIM-23268, -23190, and -23197 suppressed GH by 36$44 \%(P<0.0001)$. BIM-23268 was the most potent hormone suppressor in this experiment, suppressing GH better than octreotide and lanreotide $(P<0.05)$. Somatostatin analogues (100 nM) suppressed GH release from adenomatous cell cultures of patient 3 pituitary adenoma (Fig. $1 C$ ). Octreotide, lanreotide, and somatostatin-14 inhibited $\mathrm{GH}$ in this tumor by $19-27 \%$ of control levels $(P<0.0001)$, and BIM-23190 and -23268 by $\sim 30 \%(P<0.0001)$. Both SSTR2-selective analogues (BIM-23190, -23197; $100 \mathrm{nM}$ ) and SSTR5-selective formulations (BIM-23052, -23268) suppressed GH release in vitro (21-33\%, $P<0.0001$; and $\sim 28 \%, P<0.0001$, respectively) in cultures derived from tumor 4 (Fig. $1 D$ ). However, this somatotroph adenoma did not further suppress $\mathrm{GH}$ when treated with the novel compounds compared with octreotide (34\% suppression of control GH; $P<0.0001)$ or lanreotide $(26 \% ; P<0.0001)$.

Thus, novel somatostatin analogues with improved binding affinity for either SSTR2 or SSTR5 potently suppressed in vitro $\mathrm{GH}$ secretion from pituitary somatotroph adenomas, and usually did so more effectively than the current clinically used compounds, octreotide and lanreotide $(P<0.05)$ (See also patients 5, 6; Fig. 2, $B$ and $C$ ). Interestingly, an octreotide-resistant tumor (in vivo; tumor 1) responded in vitro to some of the novel analogues tested, but not to octreotide.

Analogue combinations. GH-cell adenoma cultures from patient 3 were used to determine possible additive effects of 


\begin{tabular}{|c|c|c|c|c|c|c|c|}
\hline No. & Sex & Age & PRL & Tumor size & DA therapy & Indication for surgery & In vitro SSTR5 response \\
\hline & & & $n g / m l$ & $\mathrm{~cm}$ & & & \\
\hline 7 & M & 64 & 742 & 1.5: noninvasive & None & Patient preference & + \\
\hline 8 & M & 33 & 1249 & 3.0; invasive & Bromocriptine & Drug compliance & + \\
\hline 9 & M & 41 & 1514 & $>3.0$; invasive & Bromocriptine & DA resistance & + \\
\hline 10 & M & 33 & 2862 & 3.4; invasive & Bromocriptine & DA resistance & + \\
\hline 11 & $\mathrm{~F}$ & 29 & 67 & 2.7; noninvasive & None & Patient preference & - \\
\hline 12 & $\mathrm{~F}$ & 27 & 150 & 0.9 ; noninvasive & Bromocriptine & DA intolerance & - \\
\hline
\end{tabular}

$D A$ resistance, Dopamine agonist resistance, defined as failure of PRL levels and tumor size to normalize on up to 20 mg bromocriptine daily.

somatostatin analogues selective for the two different receptor groups on hormone secretion. For these studies submaximal analogue concentrations $(40 \mathrm{nM})$ were used. Additive effectiveness (GH suppression, $41 \% ; P<0.0001$ ) was demonstrated by combining an SSTR2-selective analogue (BIM-23197) together with a compound selective for SSTR5 (BIM-23268; 40 $\mathrm{nM}$ ), compared with treatment by a combination of two SSTR2-selective analogues (BIM-23190, -23197; both $40 \mathrm{nM}$ )
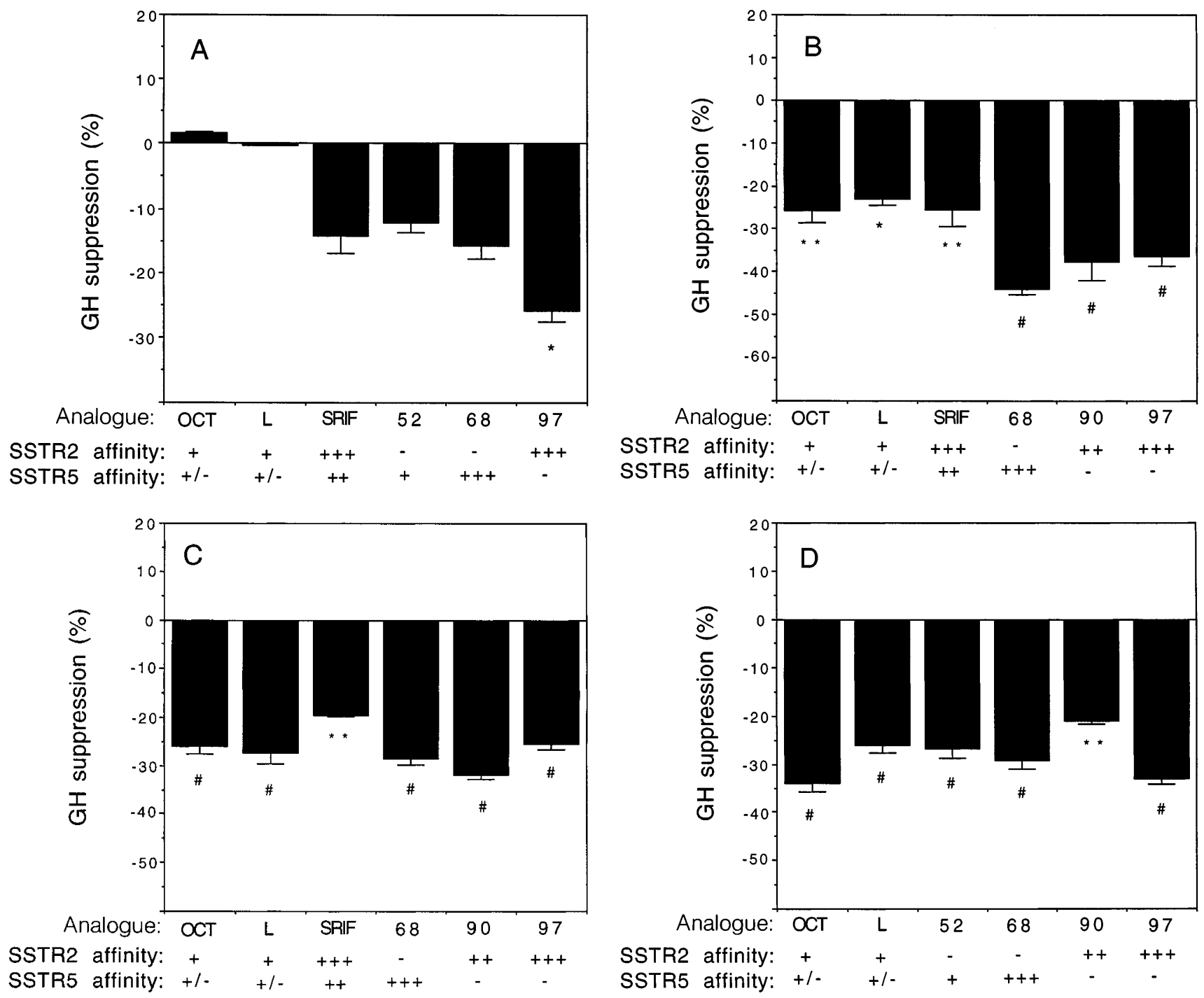

Figure 1. Human GH suppression in GH-secreting adenoma cell cultures of four different tumors treated with the indicated somatostatin analogues $(A, 10 \mathrm{nM} ; B-D, 100 \mathrm{nM})$ for $3 \mathrm{~h}$ in serum-free defined medium. Results are expressed as percent hormone suppression versus vehicletreated control wells. Each bar represents mean ( \pm SEM) GH secretion in six to eight wells. $L$, Lanreotide; $O C T$, octreotide; $S R I F$, somatostatin 14; 52, BIM-23052; 68, BIM-23268; 90, BIM-23190; 97, BIM-23197. * $P<0.05$; ** $P<0.005$; $P<0.0001$, versus control. 
which inhibited GH release by only $32 \%(P<0.01)$, or treatments by a single somatostatin analogue (either BIM-23268 or BIM-23197; each $40 \mathrm{nM}$ ). Similarly, this combination of SSTR2- (BIM-23197) and SSTR5-selective (BIM-23268, both $40 \mathrm{nM}$ ) analogues was more potent in suppressing $\mathrm{GH}$ in vitro $(42 \% ; P<0.005)$ than combined treatment with two SSTR5selective compounds (BIM-23268, -23052; $40 \mathrm{nM}$ ) or analogues used alone (Fig. $2 A$ ). This observation was confirmed in two other GH-secreting tumors (tumors 5 and 6; Fig. 2, $B$ and $C$ ). In cultures derived from both adenoma specimens, novel SSTR2- (BIM-23197) and SSTR5-selective (BIM-23268; $100 \mathrm{nM}$ ) analogues were more effective than octreotide and lanreotide in suppressing GH $(P<0.005)$, and combinations of these novel compounds (50 nM each) were 30-40\% more potent $(P<0.05)$ than equimolar concentrations of each analogue used alone. Thus, these results support the observation that both SSTR2 and SSTR5 independently regulate GH in human somatotroph adenomas.

PRL-cell adenomas. Six PRL-secreting pituitary adenomas were cultured and treated with somatostatin analogues with different binding affinities for SSTR2 and SSTR5. Adenoma
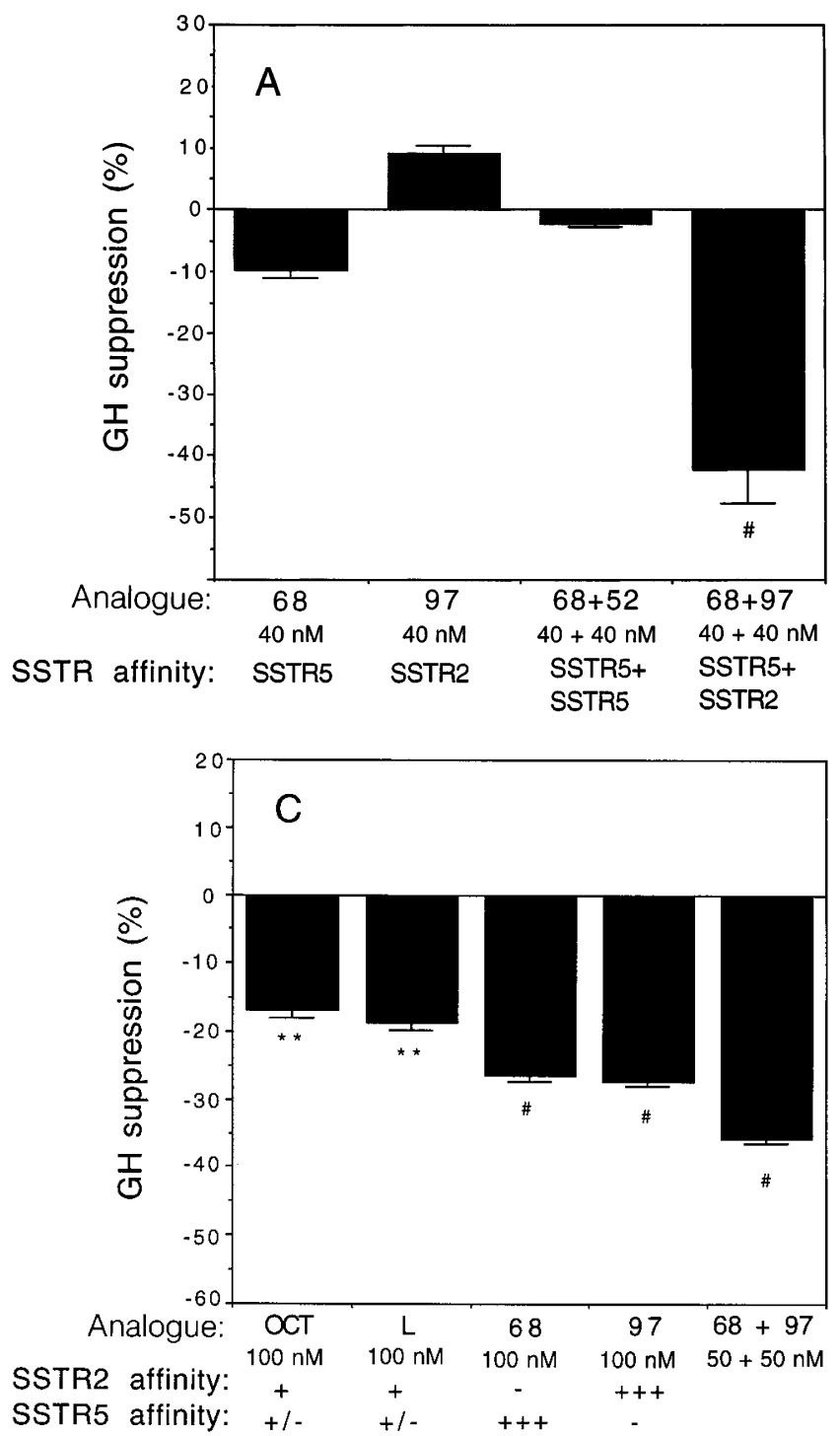

cells obtained from patients 7-10 (males harboring macroprolactinomas, three of them invasive with serum PRL $>1,000$ $\mathrm{ng} / \mathrm{ml}$; Table III) responded to SSTR5-selective analogues by suppressing in vitro PRL secretion (Fig. 3). SSTR2-preferential compounds did not suppress PRL release from these adenomatous cell cultures. BIM-23052 and BIM-23268 (10 nM) suppressed PRL secretion by 33 and $36 \%$, respectively $(P<$ 0.005 ), in cell cultures from tumor 7 (Fig. $3 A$ ). PRL release from tumor 8 lactotrophs was inhibited by treatment with 10 nM BIM-23268 (38\% versus controls; $P<0.005$; Fig. $3 B$ ). Tumor 9 cell cultures were treated with 10 and $100 \mathrm{nM}$ somatostatin analogues (Fig. 3 C), and both BIM-23268 and somatostatin-14 dose-dependently suppressed PRL by 29 and $32 \%$, respectively $(P<0.05)$. In vitro PRL release from tumor 10 was suppressed by both BIM-23052 and -23268 by $>30 \%(P<$ 0.0005; Fig. 3 D), whereas BIM-23190 and -23197 modestly stimulated PRL secretion. Interestingly, these four PRLsecreting adenomas did not respond to the clinically available drugs, octreotide and lanreotide, nor to novel analogues with even higher affinities for SSTR2. However, lactotroph tumors obtained from patients 11 and 12 (females with noninvasive

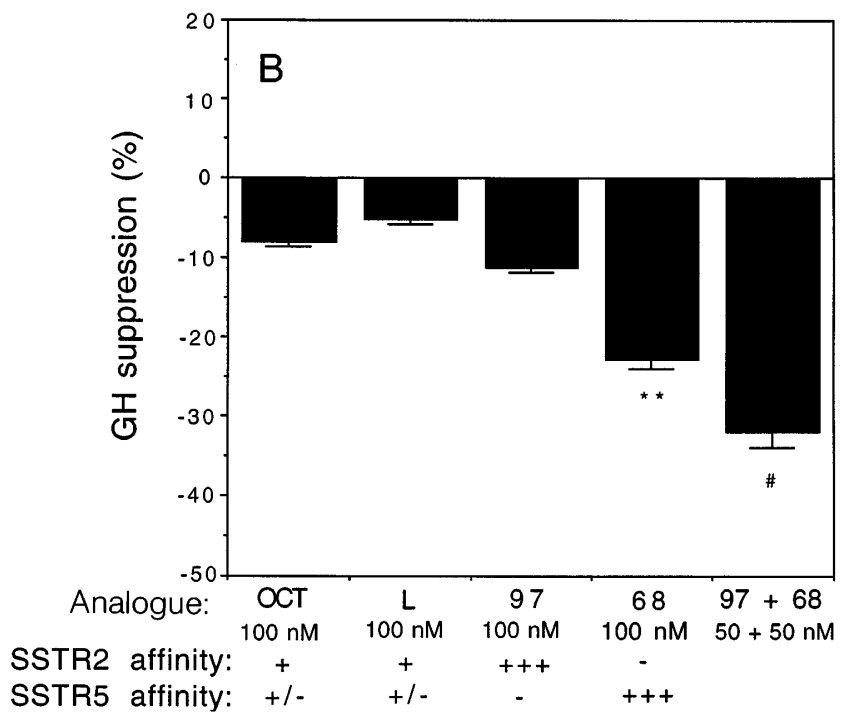

Figure 2. Human $\mathrm{GH}$ suppression in primary cultures of $\mathrm{GH}$-secreting adenomas ( $A$, tumor $3 ; B$, tumor 5 ; $C$, tumor 6 ) treated with the indicated combinations and doses of somatostatin analogues for $3 \mathrm{~h}$ in serum-free defined medium. Results are expressed as percent hormone suppression versus vehicle-treated control wells. Each bar represents mean $( \pm$ SEM) GH secretion in eight wells. $O C T$, Octreotide; $L$, lanreotide; 52, BIM-23052; 68, BIM-23268; 97, BIM-23197. ** $P<0.005$; ${ }^{\#} P<0.0005$, versus control. 

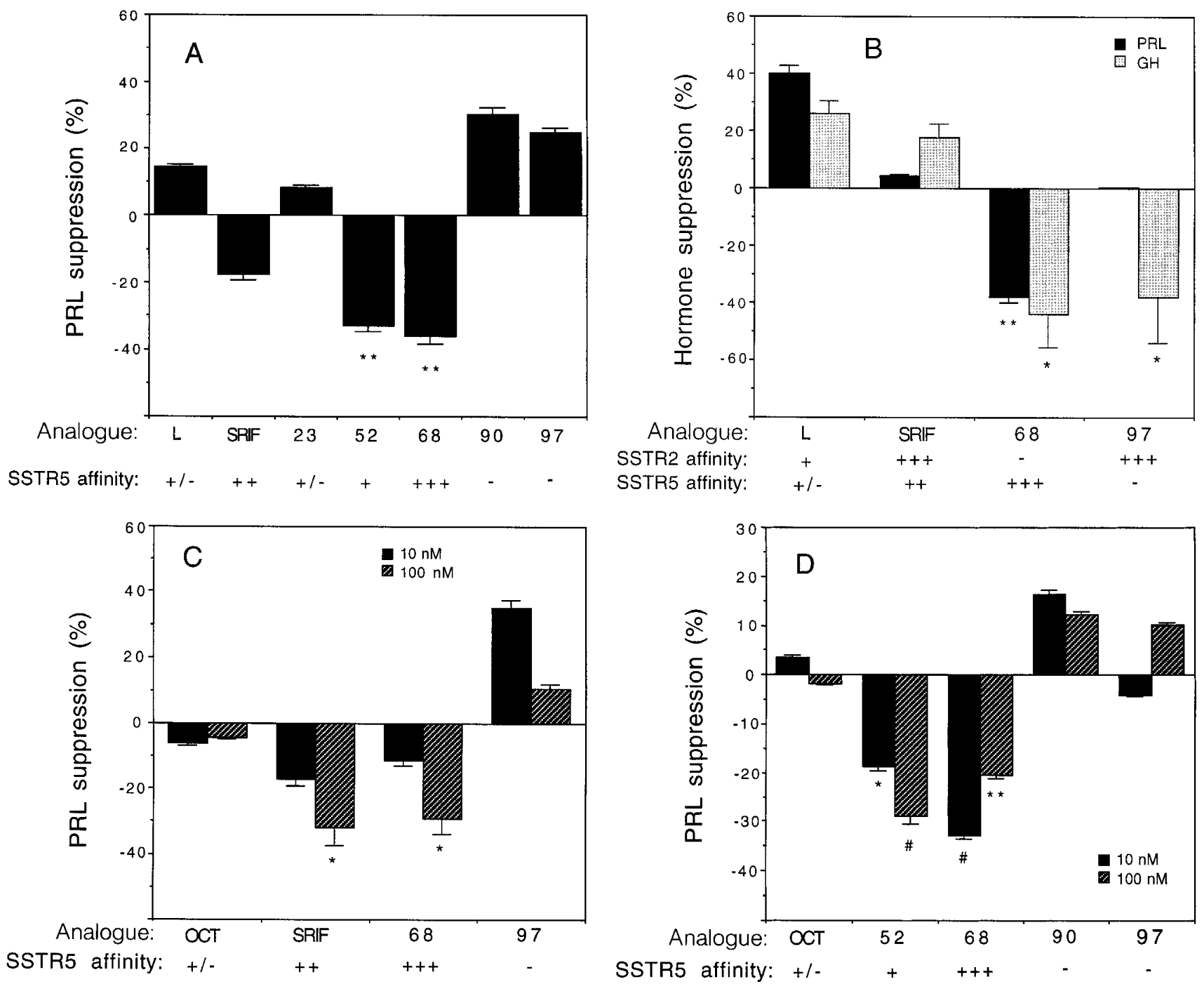

Figure 3. Human PRL suppression in primary cultures derived from four PRL-secreting adenomas treated with the indicated somatostatin analogues $(A-D$ [tumors 7-10], $10 \mathrm{nM} ; C$ and $D, 100 \mathrm{nM})$ for $3 \mathrm{~h}$ in serum-free defined medium. Results are expressed as percent hormone suppression versus vehicle-treated control wells. Each bar represents mean $( \pm$ SEM) PRL secretion in six to eight wells. Tumor $8(B)$ secreted GH in addition to PRL. L, Lanreotide; OCT, octreotide; SRIF, somatostatin 14; 23, BIM-23023; 52, BIM-23052; 68, BIM-23268; 90, BIM-23190; 97, BIM-23197. $* P<0.05 ; * * P<0.005 ;{ }^{\#} P<0.0005$, versus control.

adenomas immunostained for PRL, circulating PRL $<200$ $\mathrm{ng} / \mathrm{ml}$, and in vitro PRL secretion; Table III) did not respond to any of the somatostatin analogues examined.

PRL-secreting tumor 8 (Table III and Fig. 3 B) secreted $\mathrm{GH}$ in addition to PRL. While PRL secretion was only inhibited by an SSTR5-selective compound, GH release in the same experiment was suppressed by both SSTR2- (BIM23197, $10 \mathrm{nM}$ ) and SSTR5-specific (BIM-23268) analogues, thus further confirming the observations in pure GH-secreting tumors.

\section{Discussion}

This study using primary cell cultures of human secreting pituitary adenomas shows that somatostatin suppression of GH secretion in adenomatous cells is mediated through ligand binding to both SSTR2 and SSTR5. In contrast, PRL release from lactotroph adenoma cells is reduced via selective binding to
SSTR5 exclusively. Moreover, novel somatostatin analogues with enhanced binding affinity to either SSTR2 or SSTR5 suppress GH secretion from GH-cell adenomas in vitro more potently than the currently available analogues, octreotide and lanreotide, and combinations of SSTR2- and SSTR5-selective compounds may control hormonal oversecretion more efficiently, especially in cases of invasive and resistant tumors.

Somatotroph adenomas studied by different groups were found to express both SSTR2 and SSTR5 (11-14). Previously, we have shown that $\mathrm{GH}$ secretion from human fetal somatotrophs is mediated via these two receptors (16). We now show that both SSTR2- and SSTR5-selectively preferential analogues also mediate somatotroph adenoma cell GH secretion. Thus, $\mathrm{GH}$ regulation by somatostatin in normal (fetal) and pituitary adenoma cells in vitro is similar. Moreover, in almost all adenomas studied, including one $\mathrm{GH}$-cell adenoma previously tested (16), the new somatostatin analogues with enhanced SSTR2 binding affinities were more effective in suppressing 
GH compared with the clinically used drugs, octreotide and lanreotide. Some adenomas responded more favorably to SSTR2-preferential analogues, while in others BIM-23268 (SSTR5-selective) suppressed GH more potently. This may result from variable expression levels of SSTR2 and 5 on somatotroph adenoma cells derived from different pituitary tumors. The additive effect of SSTR2- and SSTR5-selective ligand binding on $\mathrm{GH}$ regulation in tumor cells may be even more important clinically, as it may provide a powerful medical tool to treat acromegaly, which is more efficient than the current results achieved with the available somatostatin compound, octreotide (7-9).

Somatostatin suppresses in vitro PRL secretion from prolactinomas in culture (17-19). However, in vivo somatostatin and octreotide do not alter serum PRL levels in prolactinoma patients $(20,21)$. As we have already shown the PRL suppressive effects of novel somatostatin analogues in human fetal lactotrophs (16), we now studied the ability of novel SSTR2- and SSTR5-selective analogues to inhibit PRL release from human prolactinoma cells. Lactotroph adenomas usually express both SSTR2 and SSTR5 (11-14). However, only SSTR5-selective agonists (BIM-23052, -23268) suppressed PRL release from adenomatous cells. Somatostatin-14, which binds both SSTR2 and 5 with high affinity, was also effective in one tumor (Fig. $3 C$ ). Remarkably, two of the responding tumors were resistant to dopamine agonists in vivo (Table III). The structure of BIM-23268, a compound discovered to have the highest affinity and greatest specificity thus far observed for human SSTR5, differs from the other cyclic octapeptide analogues, including octreotide and lanreotide, in that the intramolecular disulfide bridge begins and ends at the $\mathrm{NH}_{2}$ and $\mathrm{COOH}$ terminals of the peptide (positions 1 and 8) rather than positions 2 and 7 (16, 22). Interestingly, analogues with improved affinity for SSTR2 (BIM-23190, -23197) tended to mildly stimulate PRL secretion (Fig. 3, $A, C$, and $D$ ). Thus, in PRL-secreting tumors SSTR2 and SSTR5 mediate opposite effects on PRL release. Tumor 8 (Fig. $3 \mathrm{~B}$ ) demonstrates the differential suppressive effects of SSTR2 and SSTR5 on GH and PRL in pituitary adenomatous cells. In this tumor $\mathrm{GH}$ regulation was mediated via both receptor subtypes, while SSTR5 exclusively mediated PRL suppression. Thus, SSTR5-selective ligands may be effective in vivo in suppressing both hormones from pituitary adenomas secreting both GH and PRL. Two PRL-secreting adenomas did not respond to SSTR5-selective formulations, probably because of low SSTR5 expression levels on lactotroph membranes.

In contrast to human fetal cultures which responded solely to SSTR2-selective analogues (16), in the present study only SSTR5-related compounds suppressed adenomatous PRL secretion. Different profiles of SSTR subtype expression in mammosomatotrophs, the bihormonal primitive stem cells that secrete both PRL and GH in the human fetal pituitary until $24 \mathrm{wk}$ of gestation (23), or receptor or postreceptor signal transduction defects in lactotroph adenoma cells could explain this phenomenon. Recently, SSTR2 expression in human benign prostatic tissue was reported, while primary prostate cancers preferentially expressed SSTR1 (24). Thus, SSTR2 may mediate physiologic PRL secretion in the human fetus, whereas SSTR5 appears to be an important mediator of PRL suppression in prolactinoma cells.

In contrast to pituitary adenomas which express SSTR5 $(11,12,14)$, other human endocrine tumors affected by somato- statin, including carcinoids, insulinomas, glucagonomas, and pheochromocytomas express SSTR1, 2, 3, and $4(25,26)$ but not SSTR5 (26). Thus, the observed effect of SSTR5-selective analogues on adenomatous PRL secretion is probably unique, in that this group of analogues may not be useful for the treatment of other somatostatin-responsive endocrine tumors. Furthermore, potential extrapituitary effects of clinically useful SSTR5 analogues may thus differ from those of the more commonly targeted SSTR2-specific formulations.

Current efforts to improve medical treatment for PRL- and $\mathrm{GH}$-secreting adenomas include development of long-acting drug formulations to suppress PRL and GH effectively while minimizing patient inconvenience and discomfort. For prolactinomas the long-acting dopamine agonist, cabergoline, was found to be more potent than bromocriptine in suppressing PRL levels to normal (4). Sandostatin LAR (27) and slowrelease lanreotide (15), depot formulations of somatostatin analogues administered every 28 and $14 \mathrm{~d}$, respectively, are currently being evaluated in acromegalic patients. Our results in this study suggest a potential new approach to improve medical therapeutic modalities for these types of functional adenomas, using combinations of novel somatostatin formulations with higher affinity for two of the SSTRs relevant to pituitary hormone regulation.

In this study somatostatin analogues with selective affinity for SSTR5 suppressed PRL secretion from prolactinomas in culture. Remarkably, all four responsive tumors were macroprolactinomas obtained from male patients. Thus, these SSTR5-specific compounds may be effective in the treatment of PRL-secreting pituitary adenomas, and should be tested in vivo in patients with dopamine agonist-resistant prolactinomas. SSTR2- and SSTR5-selective analogues with improved receptor affinity will hopefully normalize $\mathrm{GH}$ levels in patients with invasive and resistant GH-cell tumors, and should be tested as drug combinations to ultimately achieve improved tumor shrinkage.

\section{Acknowledgments}

This work was supported by National Institutes of Health grant DK50238 (S. Melmed) and by the Doris Factor Molecular Endocrinology Laboratory.

\section{References}

1. Molitch, M.E. 1995. Prolactinoma. In The Pituitary. S. Melmed, editor. Blackwell Science, Inc., Cambridge, MA. 443-477.

2. Thorner, M.O., M.L. Vance, E. Horvath, and K. Kovacs. 1992. The anterior pituitary. In Williams Textbook of Endocrinology. J.D. Wilson and D.W. Foster, editors. W.B. Saunders Co., Philadelphia, PA. 221-310.

3. Herman, V., J. Fagin, R. Gonsky, K. Kovacs, and S. Melmed. 1990. Clonal origin of pituitary adenomas. J. Clin. Endocrinol. Metab. 71:1427-1433.

4. Webster, J., G. Piscitelli, A. Polli, C.I. Ferrari, I. Ismail, and M.F. Scanlon. 1994. A comparison of cabergoline and bromocriptine in the treatment of hyperprolactinemic amenorrhea. N. Engl. J. Med. 331:904-909.

5. Berezin., M., I. Shimon, and M. Hadani. 1995. Prolactinoma in 53 men: clinical characteristics and modes of treatment (male prolactinoma). J. Endocrinol. Invest. 18:436-441.

6. Fahlbusch, R., J. Honegger, and M. Buchfelder. 1992. Surgical management of acromegaly. Endocrinol. Metab. Clin. N. Am. 21:669-692.

7. Ezzat, S., P.J. Snyder, W.F. Young, L.D. Boyajy, C. Newman, A. Klibanski, M.E. Molitch, A.E. Boyd, L. Sheeler, D.M. Cook, et al. 1992. Octreotide treatment of acromegaly: a randomized, multicenter study. Ann. Intern. Med. 117:711-718.

8. Newman, C.B., S. Melmed, P.J. Snyder, W.F. Young, L.D. Boyajy, R. Levy, W.N. Stewart, A. Klibanski, M.E. Molitch, R.F. Gagel, et al. 1995. Safety and efficacy of long term octreotide therapy of acromegaly: results of a multi- 
center trial in 103 patients-a clinical research center study. J. Clin. Endocrinol. Metab. 80:2768-2775.

9. Melmed, S., K. Ho, M. Thorner, A. Klibanski, and S. Reichlin. 1995. Recent advances in pathogenesis, diagnosis and management of acromegaly. $J$. Clin. Endocrinol. Metab. 80:3395-3402.

10. Reisine, T., and G.I. Bell. 1995. Molecular biology of somatostatin receptors. Endocr. Rev. 16:427-442.

11. Panetta, R., and Y.C. Patel. 1995. Expression of mRNA for all five human somatostatin receptors (hSSTR1-5) in pituitary tumors. Life Sci. 56:333-342.

12. Miller, G.M., J.M. Alexander, H.A. Bikkal, L. Katznelson, N.T. Zervas, and A. Klibanski. 1995. Somatostatin receptor subtype gene expression in pituitary adenomas. J. Clin. Endocrinol. Metab. 80:1386-1392.

13. Greenman, Y., and S. Melmed. 1994. Heterogenous expression of two somatostatin receptor subtypes in pituitary tumors. J. Clin. Endocrinol. Metab. 78:398-403.

14. Greenman, Y., and S. Melmed. 1994. Expression of three somatostatin receptor subtypes in pituitary adenomas: evidence for preferential SSTR5 expression in the mammosomatotroph lineage. J. Clin. Endocrinol. Metab. 79: 724-729.

15. Caron, P., I. Morange-Ramos, M. Conge, and P. Jaquet. 1997. Three years follow-up of acromegalic patients treated with intramuscular slow-release lanreotide. J. Clin. Endocrinol. Metab. 82:18-22.

16. Shimon, I., J.E. Taylor, J. Dong, R.A. Bitonte, S. Kim, B. Morgan, D.H. Coy, M.D. Culler, and S. Melmed. 1997. Somatostatin receptor subtype specificity in human fetal pituitary cultures: differential role of SSTR2 and SSTR5 for growth hormone, thyroid-stimulating hormone and prolactin regulation. $J$. Clin. Invest. 99:789-798.

17. Ishibashi, M., and T. Yamaji. 1985. Mechanism of the inhibitory action of dopamine and somatostatin on prolactin secretion from human lactotrophs in culture. J. Clin. Endocrinol. Metab. 60:599-606.

18. Ishibashi, M., and T. Yamaji. 1985. Effects of hypophysiotropic factors on growth hormone and prolactin secretion from somatotroph adenomas in cul- ture. J. Clin. Endocrinol. Metab. 60:985-993.

19. Pellegrini, I., R. Rasolonjanahary, G. Gunz, P. Bertrand, S. Delivet, C.P. Jedynak, C. Kordon, F. Peillon, P. Jaquet, and A. Enjalbert. 1989. Resistance to bromocriptine in prolactinomas. J. Clin. Endocrinol. Metab. 69:500-509.

20. Lamberts, S.W.J., M. Zweens, J.G.M. Klijn, C.C.J. Van Vroonhoven, S.Z. Stefanko, and E. Del Pozo. 1986. The sensitivity of growth hormone and prolactin secretion to the somatostatin analogue SMS 201-995 in patients with prolactinomas and acromegaly. Clin. Endocrinol. 25:201-212.

21. Bronstein, M.D. M. Knoepfelmacher, B. Liberman, R. Marino, Jr. O.A. Germek, and A.V. Schally. 1987. Absence of suppressive effect of somatostatin on prolactin levels in patients with hyperprolactinemia. Horm. Metab. Res. 19:271-274.

22. Coy, D.H., and J.E. Taylor. 1996. Receptor-specific somatostatin analogs: correlations with biological activity. Metabolism. 45(Suppl. 1):21-23.

23. Asa, S.L., K. Kovacs, E. Horvath, N.E. Losinski, F.A. Laszlo, I. Domokos, and W.C. Halliday. 1988. Human fetal adenohypophysis. Electron microscopic and ultrastructural immunocytochemical analysis. Neuroendocrinology. 48:423-431.

24. Reubi, J.C., B. Waser, J.C. Schaer, and R. Markwalder. 1995. Somatostatin receptors in human prostate and prostate cancer. J. Clin. Endocrinol. Metab. 80:2806-2814.

25. Kubota, A., Y. Yamada, S. Kagimoto, A. Shimatsu, M. Imamura, K. Tsuda, H. Imura, S. Seino, and Y. Seino. 1994. Identification of somatostatin receptor subtypes and an implication for the efficacy of somatostatin analogue SMS 201-995 in the treatment of human endocrine tumors. J. Clin. Invest. 93 : $1321-1325$.

26. Vikic-Topic, S., K.P. Raisch, L.K. Kvols, and S. Vuk-Pavlovic. 1995. Expression of somatostatin receptor subtypes in breast carcinoma, carcinoid tumor, and renal cell carcinoma. J. Clin. Endocrinol. Metab. 80:2974-2979.

27. Kvistborg Flogstad, A., J. Halse, S. Bakke, I. Lancranjan, P. Marbach, C. Bruns, and J. Jervell. 1997. Sandostatin LAR in acromegalic patients: long term treatment. J. Clin. Endocrinol. Metab. 81:23-28. 